\title{
UMA JANELA PARA O MUNDO: REFLEXÕES SOBRE AS REDES SOCIAIS EM ESPAÇOS DE APRENDIZAGEM NO ENSINO SUPERIOR
}

\author{
Thiago Bernardo Cavassani \\ Instituto Federal do Paraná, câmpus Jacarezinho \\ Jacarezinho, Paraná \\ E-mail: thiagocavassani@yahoo.com.br

\section{Joana de Jesus de Andrade} \\ Faculdade de Filosofia, Ciências e Letras de Ribeirão Preto/USP \\ Ribeirão Preto, São Paulo \\ E-mail: joanajandrade@gmail.com
}

Resumo: Ao investigar a importância das novas tecnologias nas relações de ensino em nível superior a partir de interações pedagogicamente orientadas, o presente trabalho discute o impacto das redes sociais na educação. Com metodologia qualitativa, utilizou-se questionário e análise sociométrica (Gephi 0.8.2 Beta) das interações no grupo criado em uma disciplina de graduação e os dados são analisados à luz dos referenciais teóricos da área. Conclui-se que, apesar do grande potencial comunicativo, colaborativo e da ampliação do espaço-tempo acadêmico, os alunos não utilizam/entendem de forma unânime as redes sociais como recurso pedagógico formal. Talvez o momento de instabilidade e discordância expressa possa expor a difícil, mas necessária mudança das instituições educacionais.

Palavras-chave: redes sociais, ensino superior, facebook, cibercultura, aprendizagem, ensino superior.

\section{A WINDOW TO THE WORLD: THOUGHTS ABOUT SOCIAL NETWORKS AS LEARNING SPACES ON HIGHER EDUCATION}

Abstract: When studying the importance of new technologies on Higher Education teaching relationships using orientated pedagogical interactions, this article discusses the social network impacts on the educational field. Using a qualitative approach as questionnaires and a social analyses (Gephi 0.8.2 Beta) from interactions at a group created to be used as a tool for na under graduation subject, the data was analyzed through theoretical references coming from this field. It was concluded that even though having huge sociable, collaborative potential and the power to extend the academic space and time relationships, some students don't use/understand/see social networking as a pedagogical formal tool. Maybe this unstable and inharmonious moment is able to expose the tough, but necessary change inside the educational institutions.

Keywords: cyberculture, social network, higher education, facebook, learning, higher education.

Recebido em 30/09/2015. Publicado em 30/03/2016. 


\section{INTRODUÇÃO}

Paulo Freire defendeu como condição de seu método de alfabetização os chamados "círculos de cultura", espaços de compartilhamento, vivência e produção de conhecimento, sem hierarquias limitantes e com valorização do coletivo como forma de produção de cultura. Há mais de setenta anos o educador brasileiro confere um valor de absoluto destaque para a aprendizagem coletiva e partilhada. Entretanto, nos dias atuais as rodas e círculos de cultura/conversa/aprendizagem ganham outras faces e vão transformando a vida dos cada vez mais conectados sujeitos e 'usuários'. Caracterizados cada vez mais pela virtualidade das relações, os coletivos humanos que se encontram no espaço cibernético, configuram-se como grupos pela afinidade de interesses, pelo compartilhamento do lugar virtual e pela eterna necessidade de pertencencimento. E, se permanece ainda a expectativa e a imprevisibilidade do encontro como marcas do humano, inovadoramente desafiam-se os conceitos de espaço, de diálogo, das relações humanas e do aprender.

Os modos de aprender interpretados e descritos por diversos autores (com especial destaque no Brasil para Jean Piaget e Lev Vigotski), apesar de suas diferenças convergem na concordância de que o objeto de conhecimento, o outro e a linguagem são fundamentais para o desenvolvimento cognitivo e a constituição humana. Nesse sentido, é latente (e no caso de Vigotski é absolutamente central) o fato de que esse processo só acontece em plenitude num contexto socialmente e historicamente constituido para esse fim. É, pois, na coletividade, na mediação social e na relação com o(s) outro(s) que se revelam as atividades que potencilamente efetivam a aquisição, e produção do conhecimento.

Dessa forma, a manutenção do contato básico entre os indivíduos é condição sine qua non para o desenvolvimento de estruturas sólidas para a construção coletiva do conhecimento. Considerando-se que, na atualidade, os espaços sociais foram absolutamente transformados pelo advento das novas tecnologias, o que se observa é uma ampla difusão do consumo de tecnologias digitais impactando e potencializando novas formas de interação. A rede mundial de computadores, nesse sentido, ganha lugar de destaque ao tornar-se uma plataforma com capacidade para criar e manter redes de usuários cada vez mais conectados e aptos a formar 
coletivos inteligentes (LEVY, 1993). É a partir deste novo formato pouco hierarquizado e interativo de conexão entre os indivíduos, da oportunização de múltiplas possibilidades colaborativas de geração e ainda das inúmeras vias de compartilhamento de conhecimento que talvez estamos hoje vivenciando um momento único na história humana (PINHO, 2011).

As tecnologias digitais de informação e comunicação (TDIC) desempenham um importe papel neste sentido, possibilitando e ampliando a capacidade de ligar os usuários individuais através principalmente da rede mundial de computadores e também por garantir maior facilidade na difusão e na possibilidade de criação de conhecimento. $E$, se essas tecnologias mudam as formas de contato e interação entre as pessoas, impactam diretamente um espaço que, historicamente, tem sido lugar por excelência do aprender: a escola. No aspecto educacional, desempenham função de valorizador das práticas pedagógicas ao permitir certa flexibilização e multiplicação dos suportes de acesso, apresentação e tratamento da informação (MARTINHO; POMBO, 2009). Citando diversos autores, Marcolla (2012) afirma que:

[...] TIC possibilitam um processo diferenciado de apropriação do conhecimento, tendo em vista que permitem uma outra maneira de aproximação entre os sujeitos em formação e os diversos saberes produzidos e espalhados pelo mundo. Neste sentido, as TIC proporcionam a formação do cidadão em comunicação e interação com um mundo de pluralidades, em que as trocas de conhecimentos são constantes e extrapolam as barreiras geográficas e culturais. Deste ponto de vista, os espaços e tempos de formação deixam de ser concentrados em um local formal, e ramificam-se em diversos ambientes virtuais, que possibilitam o diálogo, a aprendizagem e a relação entre pessoas de realidades distintas (p. 2).

Ou seja, o impacto das novas tecnologias de comunicação e interação demandam novas reflexões na e da Escola/Universidade acerca de seus vários aspectos curriculares, de gestão, de objetivos e, principalmente, de identidade como grupo social. Assim, dentre as inúmeras tecnologias digitais disponíveis destacam-se as redes sociais digitais que ganharam popularidade em quases todas as camadas sociais nas mais variadas sociedades ao redor do globo e proporcionam uma verdadeira reconfiguração das formas pelas quais os relacionamentos entre os indivíduos são estabelecidas. Com tal consideração é que o trabalho aqui apresentado foi desenvolvido, pois teve como objetivo 
investigar o impacto das novas tecnologias nas relações de ensino em nível superior a partir de interações pedagogicamente orientadas em redes sociais.

Dessa forma, em consonância com as investigações atuais sobre o tema da cibercultura e da educação e na perspectiva de fomentar aos futuros professores uma práxis pedagógica alinhada à integração da cultura digital ao ambiente educacional, este trabalho trata de avaliar o uso da função grupos da rede social Facebook em uma disciplina do curso de Licenciatura em Química de uma Universidade Paulista.

\section{PERCURSO METODOLÓGICO}

O presente estudo foi realizado em duas etapas distintas. Inicialmente, foi desenvolvido e aplicado um questionário estruturado a 66 alunos do curso de Licenciatura em Química da Faculdade de Filosofia, Ciências e Letras do campus de Ribeirão Preto da Universidade de São Paulo. O questionário foi entregue aos alunos momentos antes do início do período letivo e recolhido em seguida, abarcando as turmas do primeiro ao quarto ano do curso. Baseado no trabalho de Patrício e Gonçalves (2010), desenvolveu-se um questionário para caracterização do público alvo do trabalho, com questões sobre idade, ano do curso e uma avaliação preliminar sobre suas percepções a respeito da possibilidade de uso do FB em apoio aos cursos regulares de graduação.

Já na segunda etapa, foi criado um grupo - na rede social Facebook - destinado à disciplina Atividades Científico Culturais (ACC) e o funcionamento deste grupo compõe a base para o estudo das interações aqui apresentado. A disciplina tem como objetivo "promover possibilidades para que o aluno participe ativamente de atividades científico-culturais que possam contribuir para a sua formação profissional. Introduzir o aluno nas questões educacionais presentes na sociedade, considerando tanto os aspectos culturais quanto a área específica da química ${ }^{1 ”}$. Os conteúdos abordados na disciplina, entre outros, envolviam a discussão de temas como: educação científica, aspectos ligados a educação formal, não-formal e informal, a abordagem criteriosa a respeito de conhecimento científico, escolar e cotidiano, o papel dos museus e centros de ciências além de

1 Informação disponível na ementa da disciplina, disponível em: uspdigital.usp.br/jupiterweb/obterDisciplina? sgldis=5931037\&verdis $=3$ 
outros espaços na formação científica do indivíduo. Como atividade curricular e dentro do escopo da formação de espaços para divulgação científica, os alunos foram responsáveis por estruturar, gerenciar e divulgar a Mostra de Trabalhos do Curso de Licenciatura, evento em que os alunos do curso divulgam através de pôster e apresentações orais os trabalhos que apresentaram em congressos, mostras externas ou ainda inéditos que compõe suas monografias de conclusão de curso, PCC (prática como componente curricular), IC (iniciação científica), trabalhos de extensão e tutorias.

Neste contexto, o grupo criado no FB foi estruturado para que os alunos e também o professor da disciplina divulgassem e discutissem os espaços virtuais - e presenciais - de divulgação científica, uma vez que haveria, conforme o cronograma da disciplina, um momento de tour virtual monitorado pelo docente da disciplina dentro dos espaços digitais que os próprios alunos postaram no grupo da rede social. Com a multiplicidade de possibilidades que a rede social fornece, o espaço concorreu também para a divulgação de informações administrativas da disciplina, como datas importantes, calendário, notas e o programa da disciplina; para agendamento de reuniões e apresentações, para divulgação ou discussão de assuntos referentes ao curso em geral; para divulgação de editais de seleção profissional e bolsas e para avaliação da atividade proposta no grupo. É importante ressaltar que o espaço da rede social não foi utilizado na discussão formal dos assuntos teóricos que foram tratados conforme constou do cronograma da disciplina.

O grupo Atividade Científico-Culturais 2013 contou com a participação de 23 membros. Destes, 21 eram alunos regulares da disciplina, 1 professor e um pesquisador. A análise sociométrica em si foi realizada com o auxílio do software Gephi 0.8.2 Beta. Cada participante do grupo foi codificado. Os alunos foram representados por A1 até A20 e o docente por P. Com o auxílio do software Gephi, as interações entre os participantes foram coletadas diretamente da rede social através do aplicativo Netvizz v 1.01. As informações são computadas e o software gera automaticamente uma ligação entre os usuários que, de alguma forma, interagiram. A largura da aresta reflete a intensidade da interação representada graficamente. A fig. 1 reflete a estrutura de rede gerada do grupo. Utilizando o aplicativo Netvizz v 1.01 disponível na própria plataforma da rede social e aplicando sobre o grupo criado, observa-se que é possível extrair dois grandes conjuntos de dados: 
a conexão dos amigos (friendship connection) e a interação do grupo (interactions). O primeiro, possibilita verificar as "conexões existentes entre os participantes dentro do grupo" e, no segundo caso, "são disponibilizadas as informações referentes às postagens, usuários ativos, comentários das postagens e da quantidade de gostei (likes)" ${ }^{2}$. No grupo criado no âmbito deste trabalho, as conexões dos amigos revelaram 23 nós e 152 ligações. Já a análise das interações revelou 21 usuários ativos que produziram 105 posts, comentaram ou "curtiram" 333 vezes ao longo da disciplina.

Estudar a efetividade e o impacto dos grupos em redes sociais para o processo educacional demanda diferentes perspectivas metodológicas. Devido à complexidade que estas redes podem apresentar, é necessário utilizar-se de um conjunto de técnicas que permita ordenar minimamente as interações entre os indivíduos e apresentá-las graficamente ou em forma de rede (ALEJANDRO; NORMAN, 2005). Embora a análise gráfica de uma rede social seja relevante e visualmente adequada, a utilização de medições estatísticas das interações geradas permite explicitar as características das relações observadas. Ou seja, estudar qualitativamente, neste caso, demanda que também se utilize dados quantitativos. Nesse sentido, este trabalho configurase, metodologicamente, como quali-quantitativo.

\section{RESULTADOS E DISCUSSÃO}

\section{1. $\quad$ As Rede Sociais On-Line}

Se o papel primordial das redes sociais foi a criação de possibilidades de comunicação síncrona e assíncrona, a manutenção e a criação de contatos sociais numa atividade pouco compromissada com qualquer formato de atividade formal, a funcionalidade e importância destas interfaces mudou drástica e rapidamente com a penetração social e números de adeptos destas ferramentas. É intuitivo para o usuário comum o significado do que é ou mesmo a utilidade que um determinado site de rede social desempenha. Se para alguns é uma maneira bastante simplificada para manter contato entre os amigos distanciados fisicamente ou mesmo para conectar os membros da família com mais efetividade, para outros é uma plataforma de grande

\footnotetext{
${ }^{2}$ Informações disponível no Tutorial do programa Netvizz
} 
capacidade de armazenamento e compartilhamento de fotos, formação de redes de contato profissional, promoção comercial e conglomerados empresariais, entre diversas outras possibilidades. Para cada usuário, uma mesma plataforma pode assumir inúmeras facetas, oportunizando a criação de redes e originando múltiplos significados de acordo com diferentes objetivos. Numa definição geral destas plataformas, Boyd e Ellison (2008) definem uma rede social on-line como um serviço baseado na Internet capaz de suportar a criação de um perfil público ou semi-público dentro de um sistema que permite a interação e comunicação a partir de comentários com outros usuários conectados ao mesmo em que expõe/divulga a rede de contatos dos demais usuários deste mesmo sistema.

Mazman e Usluel (2009) definem as plataformas virtuais das redes sociais como softwares de interação social que possibilitam um espaço entre indivíduos que compartilham de interesses, necessidades ou objetivos comuns. Neste ambiente suscita a colaboração coletiva, o compartilhamento de conhecimento ou mesmo a simples interação ou comunicação que suporta tanto as relações do mundo virtual quanto do real. Recuero (2009a) e Santos (2011), alinham-se a estas definições ao utilizarem o termo "softwares sociais" para descrever as interfaces capazes de comunicar sincronamente ou não os indivíduos de forma independente de sua localização geográfica. Santos (2011, p. 84) afirma que forma-se "um híbrido entre objetos técnicos e seres humanos em processos de comunicação e de construção de conhecimentos", o que justifica em partes o uso indiferenciado dos termos redes sociais e softwares sociais. Se os últimos são constituídos de um conjunto de interfaces programadas para permitir a comunicação, os primeiros são ou o conjunto de indivíduos em processo ou mesmo o próprio resultado desta ação, mediada pelas tecnologias digitais a partir de interfaces nos caso do uso da Internet (SANTOS, 2011). Recuero (2009a) complementa o disposto ao afirmar que estes sites configuram uma categoria de softwares sociais com aplicações específicas para a comunicação mediada por computador. Se até agora o foco é na estrutura dos elementos listados, a autora relembra que é na apropriação destas redes que reside a principal diferença entre as demais ferramentas mediadoras de comunicação e um site de rede social. Os últimos diferem-se no "modo como permitem a visibilidade e a articulação das redes sociais, a manutenção dos laços sociais estabelecidos no espaço off-line" (RECUERO, 2009b, p. 102-103), configurando categoria impar de ferramentas on-line de mediação de comunicação. 
Carrera (2009, apud FERRAZ, 2013) situa a rede social em ambos os campos, tanto do individual quanto do coletivo, ao afirmar que ela é composta por indivíduos e/ou por entidades, que é interligada de diversas formas e que abarca desde relações de amizades e ideias, até fluxos financeiros complexos, entre outros. Segundo o autor, as funções das redes sociais são permitir a disponibilização de um perfil on-line com informações profissionais e pessoais, permitindo a atualização destas informações e a criação de uma rede de pessoas interconectadas. Além disso, caracteriza uma rede social como uma plataforma que permite a partilha de mídias, envio de mensagens a seus membros, criação de subgrupos temáticos, organização de eventos e promoção de produtos.

A utilização de softwares na mediação de comunicação entre os indivíduos permitiu, além da já bastante salientado aumento das possibilidades de interação, compartilhamento e sociabilização, traçar mais facilmente os perfis de interação social dos indivíduos a partir da rastreabilidade das interações e conversações feitas nos ambientes on-line. Surge deste fato a expressão de rede para designação a grupos sociais suportados pelas mídias de Internet, em uma clara alusão à estrutura espacial formada pela interligação entre os indivíduos. Neste contexto, Recuero (2009b) afirma que as redes sociais são definidas a partir de dois elementos básicos: os atores, entendidos como os próprios indivíduos, instituições, conjuntos organizados; e as conexões, ou seja, os laços sociais e as interações que estes mantém entre si. Ambos os constituintes das redes assumem características distintas daquelas que ocorrem no ambiente presencial.

Portanto, se podemos definir um conceito de rede social ancorado na rede mundial de computadores, este está relacionado ao princípio básico de conectar pessoas com objetivos ou interesses comuns, cuja interação colaborativa é realizada "a partir da mediação sociotécnica e de suas conexões" (SANTOS, 2010 apud SANTOS 2011, p. 85). Tendo origens e funções diversas, estes instrumentos constituem agregadores sociais ancorados na grande rede de computadores que permitem e auxiliam a maximização das relações horizontais dos indivíduos a partir da comunicação dialógica que prescinde expressamente da presencialidade (MOURA, 2009), fator que constitui tanto uma característica única destes sistemas como também justifica a potencialidade das redes on-line em ampliar o leque de contatos sociais. 
Recuero (2009b) aponta ainda a grande capacidade de difusão de informações, a partir das conexões entre os atores das redes suportadas da Internet, como responsável pela transformação nos padrões de fluxos de informações dentro destas redes. Tal fato acarreta o surgimento de outros canais de informações entre os nós da rede e uma ampliação de novas informações circulando dentro dos grupos na rede. É a partir do fluxo de informações e contatos intercambiados continuamente entre os atores no ciberespaço, que se origina e se percebe as redes sociais. Dessa forma, "essas trocas informacionais são frequentemente associadas à construção de valor social, interação e à consequente construção (e expressão) de redes sociais na Internet [...] através de seus laços e capital social" (RECUERO, 2009a, p. 121).

Estas plataformas sociais representam hoje um fenômeno global, alcançando um número expressivo e crescente de usuários. Estas tecnologias sociais causaram grandes alterações nas formas de comunicação humana, nas formas de identificação do usuário no ciberespaço e nas mais diversas áreas das atividades sociais como o comércio, economia, a política e as relações institucionais, dentre outras; mas é no campo educacional que as redes sociais podem desempenhar um papel ainda mais impactante. Se as novas gerações de estudantes, amplamente citadas como nativas digitais ou geração alt-tab (SANTOS, 2011), convivem imersas em um ambiente estritamente on-line e em rede, é de esperar que os atores educacionais também se utilizem destas ferramentas para melhorar qualitativamente as relações de ensino /aprendizagem nos espaços escolares. Neste cenário é que surge o

[...] fenômeno da social learning, que é o processo de mudança social no qual as pessoas aprendem umas com as outras de maneira que podem beneficiar sistemas socioecológicos maiores. Dessa forma, a hiperconexão por meio das redes sociais e a Internet não apenas modifica o processo de aquisição de conteúdos/informação por meio do professor, como também - e principalmente - catalisa processos de aprendizado fora da sala de aula. Isso significa que o sistema de aprendizado está sofrendo uma profunda transformação e que isso deve ser considerado nos novos modelos educacionais, incluindo e abraçando o social learning como parte integrante e importante da educação formal (GABRIEL, p. 19). 
Em princípio é importante analisar as implicações de uso destas plataformas como auxiliares aos ambientes tradicionais de ensino, pois os diferentes usos decorrem sempre em algum impacto, seja no espaço, no funcionamento acadêmico ou na organização escolar; perpassando as sempre latentes questões de privacidade e invasão do espaço do outro. Como alunos, independentemente do grau de formação, agregam importância a estas redes sociais, permanecendo grandes períodos on-line, estas também merecem atenção nos ambientes de aprendizagem (YAPICI e HEVEDANLI, 2014), em especial a rede social de maior adesão dos alunos, o Facebook.

\subsection{O Uso Educacional do Facebook}

A literatura reporta hoje um grande número de trabalhos que abordam experiências de uso da rede social Facebook como plataformas formais e informais de ensino, tanto no ensino básico quanto nos cursos de graduação. Em aberto, fica a discussão do real papel que as mídias sociais devem exercer dentro dos espaços escolares, apesar da constatação de que os alunos, por iniciativa própria, já a utilizam como genuíno espaço colaborativo e ferramenta de compartilhamento e aprendizagem on-line (LEDERER, 2012). Bona e colaboradores (2011) afirmam que um espaço de aprendizagem digital é um "local não situado geograficamente onde o processo de ensino-aprendizagem ocorre através da organização e aplicação de uma concepção pedagógica, baseada na comunicação, interação, trabalho colaborativo do professor com os estudantes, e cooperativo dos estudantes entre si e com o professor" (p. 3). Dessa forma, o FB enquadra-se nesta definição ao apresentar:

[...] ausência de limites via Internet, ausência de disposição espacial em muitos momentos, opacidade (criação de conceitos espaciais - simulação -, associados ao espaço real, e a possibilidade de relações entre objetos neste espaço), virtualidade (que é a representação digital de algo que é real), e a telepresença (presença não física do professor, estudantes e demais agentes) (BONA et al., 2011, p. 3).

Ao permitir uma via direta, rápida e fácil de comunicação e interação on-line entre os usuários, o FB torna-se uma ferramenta ímpar para que as Escolas e Universidades melhorem a relação que mantém com seus alunos e ampliem a sua capacidade de difusão de informação para seus alunos e o público geral (BHAGWAT e KOTHARI, 2013). Dessa forma, a rede social pode ser encarada 
como uma plataforma profícua no complemento aos tradicionais ambientes de ensino/aprendizado (GUY, 2012). O FB já é utilizado em alguns casos como ambientes virtuais de aprendizado, principalmente no ensino superior, em substituição ou mesmo de forma complementar às tradicionais plataformas virtuais de aprendizagem, como o Moodle ou os Portais de cada Universidade. Meishar-Tal, Kurtz e Pieterse (2012) mostram que o uso do FB como ambiente virtual de aprendizagem suscita no aluno a percepção do ambiente como estimulador de participação, tanto pró-ativamente quanto reativamente, engendrando participação dos alunos mais retraídos. Dessa forma, o FB configura uma opção qualitativamente superior ao propiciar a percepção de um ambiente mais dinâmico e permitir uma aprendizagem colaborativa e ativa quando comparados aos já tradicionais AVA (Ambientes Virtuais de Aprendizagem) que normalmente são utilizados como repositórios de documentos.

Muitos benefícios são listados como possíveis ou decorrentes do uso da rede social nos ambientes educacionais. Dentre eles: a) aumentar a participação dos alunos em fóruns de discussão criados nestas plataformas, b) criar um ambiente eficaz com o uso de recursos de texto, imagens e recursos audiovisuais em um ambiente único e integrado, c) permitir que o aluno assuma o papel de produtor de conteúdo d) estabelecer com os recursos de mensagens instantâneas e comentários uma comunicação efetiva, fornecendo feedback mais efetivos e) compartilhar informações, ideias e fontes de consulta dentro de vários grupos com interesses comuns f) permitir que as pessoas criem seus próprios mundos e alcancem a aprendizagem social (YAPICl e HEVEDANLI, 2014).

Por outro lado, a interação que estas tecnologias trouxeram ao usuário comum facilita as relações informais, facilita ainda a constituição da identidade do indivíduo no ciberespaço, suscita o apoio mútuo e cada vez mais se destaca por permitir e fomentar a aprendizagem informal. A partir desta constatação, observa-se que cada vez mais educadores utilizam as mídias sociais para promover um ambiente de convívio informal em que possam ser ancorados processos formais de aprendizado. Neste sentido, "os professores estão usando as mídias sociais para facilitar uma cultura participativa entre os estudantes, bem como proporcionar oportunidades de auto expressão, autorreflexão e interação social em ambientes tradicionais e à distância" (GUY, 2012, p. 12). A visão dos educadores ganha relevância com a constatação de que antes do início da aula e 
até durante esta, os alunos usam o FB em seus telefones celulares e, caso seja feita uma vistoria em uma sala de informática, o FB pode ser visto aberto em até 75\% das máquinas (DENNEN et al., 2013).

Entretanto, um estudo em Singapura com 83 estudantes universitários concluiu que nenhum deles afirma usar esta plataforma em proposta educacional (HEW; CHEUNG, 2012). Outro trabalho (O'BANNON; BEARD; BRITT, 2013) também revela que o uso educacional da plataforma é uma motivação secundária do uso do FB, que contém no compartilhamento de fotos, na manutenção de relações já existentes e na comunicação direta entre os usuários as motivações principais de uso da rede social. Vidal e colaboradores (2011) também evidenciaram a falta de iniciativa dos professores universitários em propor atividades que fizessem uso da rede social em atividades de ensino, além de demonstrarem que os alunos universitários possuem atitudes positivas enquanto usuários de redes sociais, mas que poucos se mostram entusiasmados pelo uso destas tecnologias no ensino. Neste sentido, MADGE et al., (2009) revela as potencialidades da mediação social que a rede FB pode oferecer ao aluno universitário, como facilitadora no processo de adaptação à vida acadêmica e também no nível de contato dos calouros, mas também afirma para estes alunos é na componente social a maior percepção de finalidade da rede social, permanecendo as relações formais de ensino pouco aptas a serem desempenhadas nesta plataforma.

Há ainda relatos na literatura que indicam uma relação negativa entre o uso da plataforma social FB e o rendimento acadêmico de alunos (AQUINO; BRITO, 2012; KIRSCHNER; KARPINSKI, 2010) e outros que demonstram uma substancial diferença de percepção entre docentes e discentes no que diz respeito ao potencial educacional da plataforma (ROBLYER, 2010). A contradição entre os resultados sobre o uso de Facebook e o rendimento acadêmico pode ser entendido quando Junco (2012a; 2012b) apresenta estudos indicando que o uso do Facebook em si não é prejudicial ao rendimento acadêmico, mas dependendo das variáveis de análise e, principalmente, das atividades que os alunos desenvolvem dentro da plataforma, os resultados esperados em termos de aprendizagem podem ser mais ou menos efetivos. Ou seja, pode haver maior ou menor 
engajamento ${ }^{3}$ do aluno. Dessa forma, "em um ambiente natural e não guiado, os alunos usarão o Facebook de modo que seja tanto positivamente quanto negativamente relacionada ao engajamento, ao estudo e envolvimento on-campus" (JUNCO, 2012a, p.169), evidenciando a importância no processo e formatação de uso do FB e sua íntima relação com a capacidade de trazer - ou não- melhores benefícios aos alunos em sua utilização enquanto plataforma educacional.

Ao utilizar as redes sociais em apoio a atividades didáticas, seja enquanto complemento de atividades presenciais, ou mesmo como instrumento de mediação em cursos à distância, reconhece-se a importância do aluno compreender estes espaços no processo de aprendizado para o desenvolvimento de interações e identidade acadêmica em comunidades suportadas na rede e também para desenvolver visão crítica acerca da dimensão social destas redes (YAPICl; HEVEDANLI, 2014).

\subsection{Avaliação dos Questionários}

Os alunos participantes dessa fase do estudo contemplavam inscritos do primeiro ao quarto ano do curso de Licenciatura em Química e tinham faixa etária que variava de 18 a 35 anos. É imprescindível analisar preliminarmente a faixa etária do público alvo quando pretende-se desenvolver ação que faça uso da rede social FB, pois sabe-se que a adesão a esta forma de atividade digital apresenta uma correlação negativa entre a idade e uso da rede social. Ou seja, como afirma Hew (2011), quanto mais jovem é o usuário, maior a disposição no uso da plataforma FB. Dos 66 questionários avaliados, apenas um declarou não possuir conta na rede social FB, corroborando com a maior parte dos trabalhos que avaliaram índice de uso da mídia social (SALAWAY; CARUSO; NELSON, 2008; PATRÍCIO; GONÇALVES, 2010). No tocante à frequência de acesso à rede social FB, os dados revelaram uma ampla dedicação à plataforma, com mais de $80 \%$ dos alunos indicando acessar a rede social todos os dias. Mais de $10 \%$ dos alunos relataram acessar entre 4 e 6 vezes por semana, indicando alta taxa de frequência na rede.

\footnotetext{
3 "Em 1984, Alexander Astin definiu o engajamento como a quantidade de energia física e psicológica que o aluno dedica à experiência acadêmica" (JUNCO; HEIBERGER; LOKEN, 2011, p. 120).
} 
Já com relação à finalidade de uso do FB pelos alunos, os resultados indicaram mais de $90 \%$ dos alunos relatavam utilizá-lo para juntar-se a grupos de interesse comum, como grupos de estudos, associações políticas, grupos de esporte e/ou qualquer outro assunto específico. No que se refere ao uso da plataforma na transferência de documentos de aulas entre os alunos, tirar dúvidas sobre assuntos escolares ou o compartilhamento de qualquer outro material complementar com intuito acadêmico, observou a participação de 55\% dos usuários. Com relação à utilização da rede social FB para conversas mais reservadas com outros colegas ou fazer parte de transferências de arquivos confidenciais obteve porcentagem acima de $60 \%$. O uso para entretenimento da rede social, definido como tempo utilizado para visualizar as publicações dos amigos, acompanhar as alterações de status de amigos, entre outras, que configuram a função primeira dos sites de redes sociais revela a concordância de pouco mais de $40 \%$ dos alunos inquiridos.

As motivações de uso das redes sociais, em especial o FB é tema tratado em muitos trabalhos na literatura (HEW, 2011; BHAGWAT, KOTHARI, 2013, SPECIAL E LI-BARBER, 2012; JONG, et al., 2014). A grande questão a ser tratada em relação a esta análise é especificar o uso da rede na compreensão do comportamento dos usuários da rede e, no caso educacional, investigar se a rede social é ou ainda pode ser utilizada neste campo de aplicação. O principal motivo de uso das redes relatada na literatura é justamente a manutenção das relações sociais existentes (ELLISSON; STEINFIELD e LAMPE, 2007), mas outros motivos relacionados ao desenvolvimento de novos contatos, no ativismo educacional, no entretenimento e diversas outras atividades são comumente associadas ao uso do FB pelos estudantes. Os dados apresentados relatam uma concordância com os demais trabalhos reportados ao apontar a categoria de participação em grupos de interesse comum como a principal motivação de uso da rede social.

A participação nestes grupos geralmente é feita a partir de indivíduos já conhecidos ou que já possuem a relação de "amizade" dentro da plataforma e a adição de novos usuários é dependente da aceitação de um moderador que normalmente reluta em aceitar indivíduos completamente desconhecidos. Há uma tendência nesta resposta em alinhar-se com as categorias de manutenção de relações pré-existentes amplamente relatadas na literatura. Além disso, em outro viés, os grupos são formados, em sua ampla maioria, de uma relação off-line para on-line, ou seja, é a partir do contato social mantido no mundo físico entre os usuários que se oportunizam condições 
para a organização de grupos em comunidades virtuais. Portanto, é bastante seguro afirmar que a participação em grupos de interesse comum reflita o contato virtual a partir de conexões feitas no espectro presencial, pois muito do comportamento nas redes sociais reflete aquele desempenhado no mundo físico (IVCEVIC; AMBADY, 2013).

Quando questionados sobre a possibilidade de uso da rede social como ambiente virtual de aprendizado, mais de $75 \%$ dos alunos relataram concordar com tal utilização. Aproximadamente um quarto dos alunos não concorda com esta função da rede social. Novamente, os futuros professores avaliados neste trabalho concordam com os relatos da literatura (SARSAR e HARMON, 2011; 2012); IRWIN et. al (2012) em aproveitar o potencial social da plataforma também no campo educacional. Patrício e Gonçalves (2010) avaliaram que cerca de $88 \%$ dos alunos concordam com o uso do FB no apoio ao curso presencial, valores que se aproximam do expressado neste trabalho. Dessa forma, salienta-se que atividades que tentem integrar as ferramentas da Internet, em especial as redes sociais em atividades didáticas, auxiliam profundamente no engajamento dos alunos já inseridos neste contexto social digital e alinhados com os preceitos da cibercultura.

É necessário registrar a expressão dissertativa que um dos alunos deixou no questionário ao tentar justificar, ao que parece, a sua negativa em concordar com o uso do FB como suporte aos cursos presenciais ou semipresenciais: "porque as pessoas, na sua maioria, não sabem utilizar, e acabam usando para diversão e também as pessoas que trabalham ou têm outras atividades fora estudo, nem sempre têm tempo suficiente para ficar no Facebook".

Apesar de alto grau de concordância com o uso da plataforma social no uso complementar às atividades tradicionais, é necessário ressaltar que uma parcela significativa dos alunos não está disposta a engajar-se na mescla do ambiente informal e liberal das redes sociais. Sugere-se, então, que o caráter opcional da adesão às atividades educativas, independente da justificativa para tal decisão, deva ser uma constante nas práticas que pretendam utilizar-se destas ferramentas sociais, fornecendo meios para a clara compreensão dos alunos de que aqueles que porventura não aderirem às atividades mediadas pela ferramenta social não terão, em hipótese alguma, prejuízos ao seu processo de aprendizagem. 
Portanto, os alunos percebem o FB como uma possível plataforma de apoio ao ensino, como um local de repositório de documentos de fácil acesso e importante para a fluidez e velocidade da comunicação, embora uma parcela significativa deles ainda não concorde em aproveitar este genuíno espaço social para a ancoragem de processos formais de ensino.

\subsection{Análise da Função Grupos}

Com relação ao quantitativo dos dados gerados a partir da experiência de uso da função grupos em apoio às atividades de ensino, podemos compará-lo com outras publicações (CHAGAS, 2013; MINHOTO e MEIRINHOS, 2011) que estudaram a utilização do FB numa atividade educacional. A análise de uma experiência de uso da ferramenta na Disciplina de Marketing Comunicação Social do ano de 2012 (CHAGAS, 2013) obteve a participação ativa de 21 entre 45 estudantes. O número de posts efetuado foi de apenas 18 e estes obtiveram 175 ações entre "curtidas" e comentários. Já outro trabalho (MINHOTO e MEIRINHOS, 2011) analisou a página da disciplina de Biologia de 15 alunos do 12․ Ano do ensino regular no Curso Humanístico de Ciências e Tecnologias, no qual os autores classificam apenas o número total de mensagem que ultrapassou 140. Dessa forma, observa-se que no presente trabalho há um número maior de participação em número de posts entre os usuários quando comparado ao trabalho de Chagas (2013), no entanto, obtendo um número inferior de comentários em ambas as pesquisas comparadas. É necessário ressaltar que a comparação direta com o trabalho de Minhoto e Meirinhos (2011) é prejudicada quando se observa que este trabalho foi suportado com alunos do ensino médio que apresentam características distintas daqueles do ensino superior, como os desenvolvidos noutro trabalho referenciado (CHAGAS, 2013) e no presente estudo.

O número de postagens que cada usuário efetuou pode ser consultado na Tabela. 1. Observa-se que o docente efetuou 46 postagens ao longo do curso, correspondendo a mais de $40 \%$ dos posts efetuados na rede social. Além disso, há uma baixa frequência de participação dos alunos na produção de qualquer forma de conteúdo durante a experiência de uso da rede social na referida disciplina. Sete alunos (35\%) não produziram posts ao longo do curso. Dessa forma, avalia-se que a frequência de participação no grupo e o número de interações realizadas não atingiram um patamar ótimo, indicando, conforme já destacado na literatura (MINHOTO e MEIRINHOS, 2011), que a ferramenta social possibilita o compartilhamento de informações, mas denotando que 
alcançar níveis de interação e colaboração mais profundos ainda é um desafio na utilização didática das redes sociais.

O grau de centralidade indica o número de atores com o qual um determinado ator está diretamente ligado. Dessa forma, "quanto mais central é um indivíduo, mais próximo ele está em relação à troca de comunicação, o que aumenta seu poder na rede" (MARTELETO, 2001, p. 76). A medida é subdividida entre grau de entrada e saída. No primeiro caso, é descrito o número de interações que os demais atores têm com um determinado usuário e, no segundo caso, avalia as interações que este ator mantém com os demais. É, então, uma medida que pode descrever a posição que um determinado ator apresenta em relação aos demais na rede. Na análise do grupo em questão, observa-se uma posição central do docente. Ao apresentar um grau de entrada de 17, o professor desempenha um maior contato com seus alunos que estes e seus colegas, ou seja, os alunos têm maior índice de interações direcionadas ao docente, revelando ainda um modelo bastante próximo daquilo que há nas relações tradicionais em sala de aula. É necessário ressaltar que os 7 alunos que não apresentaram postagens durante a realização da atividade suportada na rede social também apresentaram grau de entrada zero, uma vez que não produziram contribuições na plataforma que pudessem gerar interação dos demais alunos/docente.

Tabela 1. Principais índices métricos calculados a partir das interações no grupo da disciplina ACC na plataforma FB.

\begin{tabular}{|c|c|c|c|c|c|c|}
\hline Item & Post & Grau de entrada & Grau de saída & Excentricidade & $\begin{array}{c}\text { Centralidade de } \\
\text { Proximidade }\end{array}$ & $\begin{array}{c}\text { Centralidade de } \\
\text { Intermediação }\end{array}$ \\
\hline $\mathrm{P}$ & 46 & 17 & 10 & 2.0 & 1,308 & 88,99 \\
\hline A1 & 4 & 2 & 8 & 2.0 & 1,385 & 2,19 \\
\hline $\mathrm{A} 2$ & 5 & 5 & 7 & 2.0 & 1,538 & 0,34 \\
\hline A3 & 3 & 2 & 9 & 2.0 & 1,308 & 3,91 \\
\hline A4 & 8 & 7 & 7 & 2.0 & 1,538 & 5,46 \\
\hline A5 & 13 & 15 & 10 & 2.0 & 1,308 & 57,9 \\
\hline A6 & 0 & 0 & 3 & 2.0 & 1,786 & 0 \\
\hline A7 & 1 & 2 & 4 & 2.0 & 1,692 & 0,78 \\
\hline A8 & 5 & 9 & 9 & 2.0 & 1,385 & 15,4 \\
\hline A9 & 0 & 0 & 6 & 3.0 & 1,643 & 0 \\
\hline A10 & 3 & 11 & 3 & 2.0 & 1,846 & 5,8 \\
\hline A11 & 3 & 9 & 4 & 2.0 & 1,769 & 1,53 \\
\hline
\end{tabular}


Cavassani e Andrade, 2016 - Tecnologia Educacional

\begin{tabular}{c|c|c|c|c|c|c}
\hline A12 & 4 & 4 & 4 & 3.0 & 1,923 & 1,8 \\
\hline A13 & 0 & 0 & 2 & 3.0 & 2,214 & 0 \\
\hline A14 & 6 & 11 & 8 & 2.0 & 1,462 & 1,82 \\
\hline A15 & 0 & 0 & 4 & 2.0 & 1,714 & 0 \\
\hline A16 & 2 & 1 & 2 & 3.0 & 2,231 & 0 \\
\hline A17 & 2 & 11 & 2 & 3.0 & 2,077 & 0 \\
\hline A18 & 0 & 0 & 2 & 2.0 & 1,857 & 0 \\
\hline A19 & 0 & 0 & 1 & 3.0 & 2,214 & 0 \\
\hline A20 & 0 & 0 & 1 & 3.0 & 2,214 & 0 \\
\hline
\end{tabular}

Com relação ao grau de saída, observa-se que os alunos A5, A10, A14 e A17 também apresentaram uma atividade próxima ao ator central representado pelo docente, o que é bastante significativo quanto ao volume de interação que pode ocorrer em ambientes suportados pela mídia social. Neste caso, observa-se que o aluno A5 representa um papel também centralizado na catálise das interações que acontece no grupo estruturado nesta rede social. O grau de saída do ator central é equivalente ao aluno A5 e bastante próximo dos alunos A1 e A8. Neste quesito, ao observar a iniciativa dos alunos em interagir com os demais colegas, novamente o ator A5 tem papel de destaque na coesão e atividade do grupo.

A centralidade do docente é também reportada como uma questão problemática no uso destes recursos em complemento às atividades didáticas. Conforme indica Minhoto e Meirinhos (2011), o fato dos alunos ainda comporem os bancos do ensino secundário justifica, na opinião dos autores, a centralidade do processo na pessoa do professor, revelando a franqueza da rede que, na ausência deste, fragiliza a ponto de inviabilizar a manutenção das relações do grupo. Há que se pensar, entretanto, outro fator ignorado pelo referido trabalho. Quando o professor faz comentários e "curte" as contribuições de seus alunos, reflete ordinariamente a dedicação deste em fornecer um feedback e um esforço primordial na manutenção do interesse do aluno dentro da atividade proposta. Ao participar ativamente em comentários e likes dentro da plataforma, o professor reforça positivamente seus alunos a continuar comunicando-se com seus pares e interagir dentro da rede, além de registrar que sua contribuição foi de alguma forma vista e avaliada pelo responsável pela disciplina. 
Neste sentido, a discussão traçada alinha-se ao já aventado por outros autores que afirmam ser necessário criar, ao utilizar o FB em atividades didáticas, "metodologias de abordagem que estimulem o interesse dos alunos na participação das atividades propostas pelo professor e neste processo o professor deve ser sempre a figura central desta relação" (PAIXÃO et al., 2012, p. 2431). Dessa forma, se a centralidade do professor é uma realidade do modelo tradicional de ensino, a análise estatística destes parâmetros nas diversas interações que emergem dentro das redes sociais deve ser cautelosa para não subjugar ou mesmo subestimar o papel interativo, comunicativo e colaborativo que exerce o professor nas novas e ainda em desenvolvimento formas de ensinar e aprender. É importante ressaltar, por fim, que todos os alunos apresentaram grau de saída diferente de 0 , ou seja, até mesmo aqueles alunos que não fizeram postagens durante a disciplina mantiveram alguma forma de interatividade na plataforma, comentando ou curtindo os posts dos colegas e do docente.

Na rede avaliada, observa-se a figura do professor e também do aluno A5 com os maiores valores de intermediação, significando que, além de ocuparem posição central na rede, ainda trabalham no intuito de facilitar a transferência de informação aos demais usuários. O grau de proximidade avalia o quanto cada ator aproxima-se dos demais componentes da rede (MACHADO, 2013). Ou seja, esta métrica "representa a capacidade que um ator possui de alcançar os demais. Dessa forma, essa medida representa quanto um ator alcança os nós da rede, o que mede a sua independência de atuação na rede em relação à atuação de outros atores" (BORSATO, KAUCHAKJE e ROCHADELLI, 2010, p. 360). Rossoni e colaboradores (2010) afirmam que o cálculo dessa medida é realizado a partir das somas das distâncias geodésicas entre todos os atores, indicando a centralidade global dos atores. No caso do software utilizado, quanto mais próximo de 1, maior é a proximidade que os usuários estão dos demais atores da rede. O professor e o aluno A3 correspondem aos atores mais próximos dos demais componentes da rede ao apresentar o menor caminho entre eles, com valor próximo de 1,30 .

Outro parâmetro que também pode ser avaliado é a densidade da rede, que representa um quociente entre o número de ligações efetuadas e a totalidade das ligações possíveis na configuração da rede analisada. Este parâmetro analisa, portanto, o grau de conectividade da rede, expresso em porcentagem. Na rede em questão, a partir dos dados gerados pelo software Gephi, a densidade calculada é de 25,2\%. O valor encontrado revela-se baixo quando se avalia que 
a rede social pretende, na perspectiva adotada neste trabalho, colaborar com interação, troca de informações e conectividade dos alunos. No entanto, este valor é compatível com os demais valores reportados na literatura. No trabalho de Minhoto e Meirinhos (2011) a densidade é pouco superior a 22\%, enquanto Chagas (2013) apresenta densidade pouco superior a $20 \%$. Portanto, parece ser uma constante em trabalhos que envolvem o uso educacional do FB um baixo índice de conectividade de seus membros.

Outro fator a ser analisado é a excentricidade, que mede a distância entre um nó e todos os demais nós do grafo. Nascimento (2013) destaca que quanto menores são os valores de excentricidade, melhor é a posição em relação aos demais nós da rede e quanto mais relacionamentos diretos um ator possui, menor é a necessidade de intermediadores. Analisando a tab. 1, observa-se que os valores de excentricidade são bastante homogêneos, cujas maiores distâncias entre os nós são dos atores com menor participação na atividade proposta.

Já o grau de intermediação avalia o quanto um ator está ligado aos outros atores (MACHADO, 2013). Esta medida é realizada pela contagem de todos os caminhos mais curtos entre quaisquer dois indivíduos na rede, indicando os atores responsáveis pela transferência de informação entre as diferentes partes da rede não possuindo, muitas vezes, o menor caminho médio entre os demais usuários, mas sim o maior número de caminhos mais curtos que necessariamente passam por este nó (ACTIVE NETWORK, 2014). Em redes maiores, as medidas de centralidade, como o grau de intermediação configuram uma importante medida na distribuição dos usuários. Ou seja, o grau de intermediação é também uma medida da importância destes nós ao grafo (fig. 1) ao indicar a quantidade de caminhos mínimos que passam por este ator (NASCIMENTO, 2013).

A análise do grafo gerado (Figura 1) permite visualizar que o tipo de rede emergente da interação entre os alunos e o docente indica a ausência de subgrupos dentro da rede estabelecida, indicando que a estrutura formada pelas inter-relações dos alunos na experiência de uso do FB abarca a totalidade dos usuários, configurando um trabalho colaborativo e integrado distribuído pela rede formada, não oportunizando a fragmentação do grupo pertencente à estrutura. Estes dados são consonantes com o já repostado na literatura (FERREIRA, 2012). 


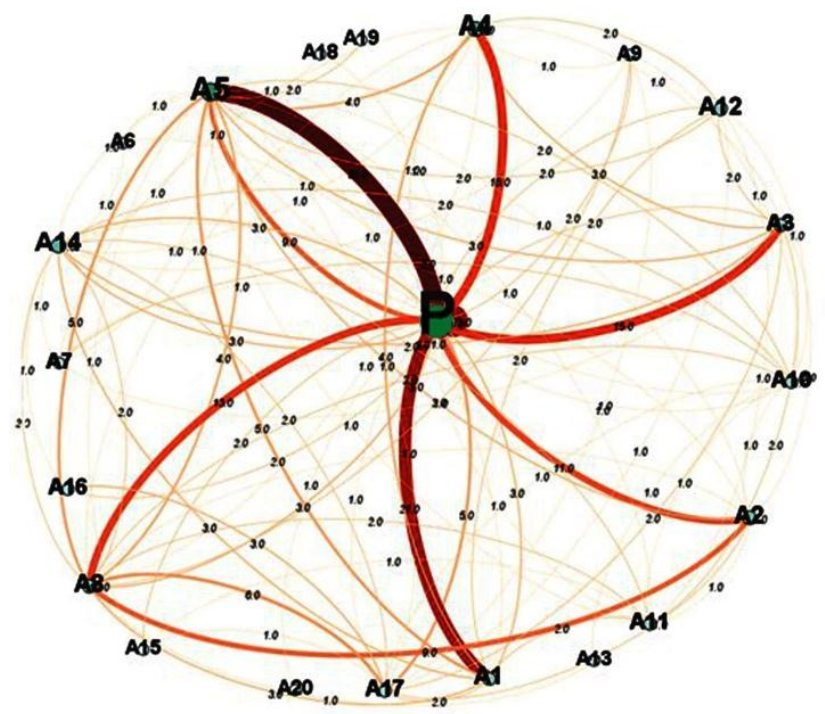

Figura 1. Representação gráfica gerada a partir das interações do grupo ACC 2013 na rede social Facebook.

\section{CONSIDERAÇÕES FINAIS}

Partindo do pressuposto que o FB pode ser entendido como uma interface que representa inovação e possibilidade de construção coletiva do conhecimento, fornecendo situações únicas na experimentação de virtualidade (ANDRADE, AZEVEDO e DÉDA, 2012) avaliou-se a possibilidade de integração da rede social de maior adesão mundial e mais utilizada entre os alunos universitários complementarmente às atividades presenciais do curso de Licenciatura em Química. Entendendo que:

[...] fazer uso de redes sociais na educação pode ser considerado uma estratégia para um caminho da produção e compartilhamento do conhecimento. É preciso ter clareza que o compartilhamento da informação e do conhecimento, no Facebook, por exemplo, só terá implicações significativas se provocar um processo de aprendizagem, já que o simples uso dessas ferramentas pode não tem caráter transformador da realidade (FLORES; CARLOTO, 2013, p. 3).

No trabalho desenvolvido, percebeu-se que a rede social proporcionou o compartilhamento de materiais, a criação de um espaço próprio para a comunicação dos alunos e entre estes e a docente; um local de construção de grupos de trabalho assíncrono. No entanto, não se observou, mediante os resultados demonstrados, mediação direta e formal dos conteúdos abordados em 
sala de aula. O grafo da interação dos alunos é um indicador de que a ferramenta alcançou seu objetivo de potencializar a comunicação entre os alunos e fornecer um ambiente propício para a extensão das relações de ensino além dos muros da academia, um local adequado para a interação e para a partilha de materiais entre os envolvidos no processo de ensino e aprendizagem. Conforme já destacado, os níveis mais profundos de interação ainda são difíceis de serem alcançados quando se utiliza o FB como ferramenta de ensino, mas corresponde a uma ferramenta ímpar no trabalho colaborativo dos alunos.

Se a possibilidade para uma aprendizagem efetiva por meio da rede social parece ficar ainda aquém dos objetivos de uma disciplina escolar/universitária, outros aspectos desse ambiente se mantém: a centralidade do professor, o aluno de destaque, a identidade de um grupo que 'estuda' junto para chegar a um objetivo comum. Como a disciplina ACC é presencial, os alunos se encontraram semanalmente, mas, obviamente, o "tempo de aula" e "o espaço da sala" foram ampliados por meio do uso das novas tecnologias e não podem ser medidos com exatidão. E esse parece ser um dos legados mais interessantes dessa nova cultura de educação virtual. A autonomia, a atitude responsiva e ativa, "o aprender a aprender" e a responsabilidade pela construção de certo currículo acadêmico acabam ficando mais claros quando se investiga os impactos da cibercultura na educação.

Dessa forma, conclui-se que o FB é uma ferramenta bastante conveniente no desenvolvimento de experiências colaborativas entre os alunos, na facilitação da comunicação entre estes e seus professores e na melhoria da relação geral que permeia o processo de ensino e aprendizagem. Os alunos percebem e utilizam por iniciativa própria as potencialidades positivas oferecidas a partir da utilização da rede social no ambiente acadêmico, embora uma parcela significativa deles ainda não esteja disposta a utilizar a ferramenta em processos formais de ensino. Se a aprendizagem é, por princípio, um processo claramente social, o FB desempenha um papel primordial na alavancagem e na facilitação do contato básico para que esta ação se desenvolva, mas não é, como sugerem os dados demonstrados, local ideal para a mediação formal dos conteúdos trabalhados em sala de aula. Conforme Tsukamoto e colaboradores (2014), as redes sociais representam para educação uma janela para o mundo ao expandir as formas de comunicação e permitir um grande fluxo de informação de forma aberta e flexível que colaboram na construção 
do conhecimento. Entretanto, sua plena integração ao processo educacional ainda constitui um grande desafio. Este talvez deva ser um objetivo a ser buscado pelas futuras gerações no intuito de contemplar este aspecto. Ou seja:

[...] a educação presencial é apenas uma das dimensões em que a educação acontece envolvendo o corpo biológico. Como os estudantes estão "esparramados" pelas plataformas digitais, para conseguirmos alcançá-lo plenamente precisamos atingir as suas dimensões digitais também, como e-mail, perfis em redes sociais (Twitter, Facebook etc.) A necessidade de alcançar as várias partes digitais dos estudantes distribuídos pelas diversas plataformas (além do seu corpo biológico) requer uma comunicação mais fragmentada, não linear e hipertextual, em vez de uma educação/comunicação linear, que é característica da educação tradicional (GABRIEL, 2013, p. 59).

Assim como o e-mail tornou-se um veículo oficial na comunicação entre as instituições escolares e seus alunos- bem como em praticamente qualquer instituição- ou mesmo os sites disponíveis na Internet promovem a comunicação direta e ampla com seus usuários, as tecnologias sociais iniciam sua participação na mudança dos paradigmas de comunicação institucional; e com isso afetam também as relações de ensino. Ao proporcionar o uso da rede social FB no convívio dos alunos em suas experiências de ensino e aprendizagem, os professores poderão, paulatinamente, criar nos usuários a consciência de uma ferramenta apta ao ensino, galgando espaço para que este se torne um genuíno ambiente colaborativo na mediação do ensino formal nas instituições de ensino superior.

Na experiência aqui relatada cabe destacar que a disciplina em questão tinha como ementa conhecer lugares de divulgação da ciência, compartilhar experiências diferenciadas de educação formal, informal e não formal. Nesse sentido, é importante ressaltar o fato de que aquilo postado ao longo do semestre, em sua maioria, referia-se ao mundo fora da Universidade e, principalmente, ao universo de possibilidades da educação e da ciência fora das salas de aula: museus interativos pelo mundo todo, vídeos sobre os diversos espaços e tipos de educação, divulgação de eventos sobre ciência, arte e divulgação científica, vídeos de palestras educacionais e motivacionais, jogos interativos e laboratórios virtuais, vídeo aulas nacionais e internacionais, 
textos, fotos, vídeo produzidos pelos próprios alunos, dentre tantas outras coisas. A quantidade de conhecimentos apropriados e a curiosidade despertada nos alunos foram grandes e certamente impossível de alcançar com o simples uso de lousa, giz e mesmo a melhor intenção e dedicação na atividade do professor.

Ou seja, se as redes sociais não podem ser ainda consideradas totalmente confiáveis ou recomendáveis ao uso educacional formal, talvez seja necessário que os professores e as instituições de ensino revejam se o sentido da adequação não poderia ser também a inversa. Cabe questionar, portanto, como as metodologias de ensino, as concepções sobre conhecimento, os conteúdos conceituais, atitudinais e procedimentais, etc., poderiam ser ensinados também de modo virtual. Ao invés de simplesmente afirmar que ainda não é oportuno colocar nas redes sociais on-line o conteúdo tradicional da escola/Universidade, será que não seria o caso de colocar na escola/Universidade o conteúdo das redes sociais explorando novas metodologias de ensino, menos centralizadas no professor, mais criativas e com maior ênfase ao processo autônomo e independente do aluno?

É bastante recorrente a afirmação entre os pesquisadores em educação que as instituições de ensino precisam mudar. São comuns discursos de que a escola está obsoleta e, mais ainda, que é claro o fato de que qualquer espaço da convivência humana (como meios de transporte e de comunicação, as casas, os eletrodomésticos, os móveis, etc.) mudou muito nos últimos anos. Tais afirmações confrontam com a realidade das instituições de ensino brasileiras que continuam utilizando recursos típicos do início do XX como únicas formas de recurso pedagógico. Os dados encontrados na presente pesquisa talvez estejam mostrando justamente esse conflito de discursos e realidades: os professores, os alunos e a escola, não sabem ainda como mudar e por isso negam, encontram dificuldades, e preferem manter as vias oficiais como formas seguras de fonte de aprendizagem. Mudar demanda esforço, readaptações, inovações e talvez por isso haja ainda a afirmação de que as novas tecnologias não funcionam completamente na escola. Quem sabe esse momento de revolução pós-moderna, de falta de fundamentos sólidos, de modernidade líquida, não nos possa brindar com esta difícil, mas absolutamente necessária, mudança das instituições educacionais! 


\section{REFERÊNCIAS}

ACTIVE NETWORK. Who is central to a social network? It depends on your centrality measure. Disponível em: <http://www.activatenetworks.net/>. Acesso em: 10 nov. 2014.

ALEJANDRO, Velázquez AO; NORMAN, Aguilar G. Manual introdutório à análise de redes sociais. UAEM-Universidad Autonoma Del Estado de México, 2005.

ANDRADE, Polyana Bittencourt; AZEVEDO, Denio Santos; DÉDA, Talita de Azevedo. Práticas de Ensinagem e Redes Sociais na Internet: um estudo de caso do Facebook como ambiente de aprendizagem. In: Simpósio Educação e Comunicação - infoinclusão: possibilidades de ensinar e aprender, 3., 2012, Aracajú. Anais do... Aracajú. Universidade Tiradentes - UNIT. p. 301-316, 2012.

AQUINO, Alex; BRITO, Alisson. Estudo da Viabilidade do Uso do Facebook para Educação. Em: Workshop sobre Educação em Informática, 20. Anais do... Curitiba: Sociedade Brasileira de Computação, 2012. 10 p.

BHAGWAT, Minaxi; KOTHARI, R. G. Encouraging social media with school education. Edulnspire: An International EJournal, v. 1, n. 1, p. 12-18, 2013.

BONA, Aline Silva de; BASSO, Marcus Vinicius de Azevedo; FAGUNDES, Léa da Cruz. A cooperação e/ou a colaboração no Espaço de Aprendizagem Digital da Matemática. RENOTE, v. 9, n. 2, 2011.

BORSATO, Regiane; KAUCHAKJE, Samira; ROCHADELLI, Roberto. Rede de responsabilidade socioambiental: uma metodologia para análise no setor de celulose e papel. Revista Árvore, v. 34, n. 2, p. 355-365, 2010.

BOYD, Danah M.; ELLISON, Nicole B. Social Network Sites: Definition, History, and Scholarship. Journal of computermediated communication, v. 13, n. 1, p. 210-230, 2008.

CHAGAS, Alexandre Meneses. A contribuição do facebook no processo da aprendizagem colaborativa. 2013. 224p. Dissertação (Mestrado em Educação)- Universidade Tiradentes, Aracajú, 2013

DENNEN, V. P., HAO, S., TACKETT-BRADT, S., BRADT, W. The university library commons as third place: Virtual and social dimensions of learning support. Paper presented at the American Educational Research Association, San Francisco, CA, 2013.

ELLISON, N.B.; STEINFIELD, C.; LAMPE, C. The benefits of Facebook "friends:" Social capital and college students' use of on-line social network sites. Journal of Computer-Mediated Communication, v. 12, n. 4, p. 1143-1168, 2007.

FERRAZ, Pedro. A importância das Redes Sociais On-line em Instituições de Ensino Superior: Estudo de Caso do Facebook da Universidade Atlântica. Dissertação (Mestrado em Gestão). Universidade Atlântica. 91p. 2013

FERREIRA, Carla Isabel Valentim. Recursos educativos digitais no ensino de física e química: um estudo com alunos do 7ํ ano de escolaridade. Dissertação (Mestrado em Didáctica das Ciências). Universidade de Lisboa, 166p. 2012.

FLORES, Elaine Aparecida Pereira; CARLOTO, Viviane Perufo. O facebook e suas possibilidades literárias. Salão do Conhecimento. In. Salão do Conhecimento: Ciência, tecnologia e desenvolvimento social, 2013, ljuí. Anais do... ljuí: Universidade Regional do Noroeste do Estado do Rio Grande do Sul, 2013.

GABRIEL, Martha. Educ@ r: a (r) evolução digital na educação. São Paulo: Saraiva, 2013.

GUY, Retta. The use of social media for academic practice: A review of literature. Kentucky Journal of Higher

Education Policy and Practice, v. 1, n. 2, p. 7, 2012. 


\section{Cavassani e Andrade, 2016 - Tecnologia Educacional}

HEW, K. F. Students' and teachers' use of Facebook. Computers in Human Behavior, v. 27, n. 2, p. 662-676, 2011.

HEW, Khe Foon; CHEUNG, Win. Sun. Use of Facebook: A case study of Singapore students' experience. Asia Pacific Journal of Education, v. 32, n 2, p. 181-196, 2012.

IRWIN, Christopher et al. Students' perceptions of using Facebook as an interactive learning resource at university. Australasian Journal of Educational Technology, v. 28, n. 7, p. 1221-1232, 2012.

IVCEVIC, Zorana; AMBADY, Nalini. Face to (face) book: the two faces of social behavior? Journal of personality, v. 81 , n. 3, p. 290-301, 2013.

JONG, Bin-Shyan et al. An exploration of the potential educational value of Facebook. Computers in Human Behavior, v. 32, p. 201-211, 2014.

JUNCO, Reynol. The relationship between frequency of Facebook use, participation in Facebook activities, and student engagement. Computers \& Education, v. 58, n. 1, p. 162-171, 2012a.

JUNCO, Reynol. Too much face and not enough books: The relationship between multiple indices of Facebook use and academic performance. Computers in Human Behavior, v. 28, n. 1, p. 187-198, 2012b

JUNCO, Reynol; HEIBERGER, Greg; LOKEN, Eric. The effect of Twitter on college student engagement and grades. Journal of Computer Assisted Learning, v. 27, n. 2, p. 119-132, 2011

KIRSCHNER, Paul Arthur; KARPINSKI, Aryn. Facebook ${ }^{\circledR}$ and academic performance. Computers in human behavior, v. 26, n. 6, p. 1237-1245, 2010.

LEDERER, Karen. Pros and cons of social media in the classroom. Campus Technology, v. 25, n. 5, p. 1-2, 2012.

LÉVY, Pierre. A Inteligência coletiva . Edições Loyola, 1993.

MACHADO, Raymundo das Neves. Produtividade dos autores em ceratocone: estudo longitudinal em artigos indexados no SciELO Brasil (2001-2010). RDBCI, v. 11, n. 1, p. 1-20, 2013.

MADGE, Clare; MEEK, Julia; HOOLEY, Tristram. Facebook, social integration and informal learning at university: "It is more for socialising and talking to friends about work than for actually doing work". Learning, Media and Technology, London, v. 34, n. 2, p. 141-155, 2009.

MARCOLLA, Valdinei. A apropriação das tecnologias de informação e comunicação por professores nas práticas pedagógicas. SEMINÁRIO pesq. em educ. da região sul. Anais do... Universidade de Caxias do Sul, 2012.

MARTELETO, Regina Maria. Análise de redes sociais - aplicação nos estudos de transferência de informação. Ciência da Informação, v. 30, n. 1, p. 71-81, 2001.

MARTINHO, Tânia; POMBO, Lúcia. Potencialidades das TIC no ensino das Ciências Naturais - um estudo de caso. Revista Electrónica de Enseñanza de las Ciencias, v. 8, n. 2, p. 527-538, 2009.

MAZMAN, Sacide Güzin; USLUEL, Yasemin Koçak. The usage of social networks in educational context. World Academy of Science, Engineering and Technology, v. 49, p. 404-408, 2009.

MEISHAR-TAL, Hagit; KURTZ, Gila; PIETERSE, Efrat. Facebook groups as LMS: A case study. The International Review of Research in Open and Distance Learning, v. 13, n. 4, p. 33-48, 2012.

MINHOTO, Paula; MEIRINHOS, Manuel. As redes sociais na promoção da aprendizagem colaborativa: um estudo no ensino secundário. Educação, Formação \& Tecnologias, v. 4, n. 2, p. 25-34, 2011. 
MOURA, Maria Aparecida. Informação e conhecimento em redes virtuais de cooperação científica: necessidades, ferramentas e usos. DataGramaZero: Revista de Ciência da Informação, v. 10, n. 2, 2009 n. 2, p. 141-155, 2009.

NASCIMENTO, C. PANDORA-Uma Ferramenta para Visualização Incremental e Análise de Redes Sociais Acadêmicas. 84p. Dissertação (Mestrado em Ciências da Computação). UFRGS. Porto Alegre, 2013.

O'BANNON, Blanche W.; BEARD, Jeffrey L.; BRITT, Virginia G. Using a Facebook Group As an Educational tool: Effects on student achievement.Computers in the Schools, v. 30, n. 3, p. 229-247, 2013

PAIXÃO, Alexsandro Figueiredo da, et al. Redes sociais e educação: o facebook enquanto um espaço com potencialidades para o ensino superior de matemática? In: Congresso Internacional TIC e Educação, 2., 2012, Lisboa. Anais do... Instituto de Educação da Universidade de Lisboa, p. 2423-2435, 2012

PATRÍCIO, R.; GONÇALVES, V. Facebook: Rede Social Educativa. Em I Encontro Internacional TIC e Educação. TicEduca I Encontro Internacional TIC e Educação. Lisboa: Instituto de Educação - Universidade de Lisboa, 2010.

PINHO, José Antonio Gomes de. Sociedade da informação, capitalismo e sociedade civil: reflexões sobre política, Internet e democracia na realidade Brasileira. Revista de Administração de Empresas, v. 51, n. 1, p. 98-106, 2011.

RECUERO, Raquel. Diga-me com quem falas e dir-te-ei quem és: a conversação mediada pelo computador e as redes sociais na Internet.Revista FAMECOS: mídia, cultura e tecnologia, v. 1, n. 38, 2009a .

RECUERO, Raquel. Redes sociais na Internet. Porto Alegre: Sulina, 2009b.

ROSSONI, Luciano; HOCAYEN-DA-SILVA, Antônio João; JÚNIOR, Israel Ferreira. Aspectos estruturais da cooperação entre pesquisadores no campo de administração pública e gestão social: análise das redes entre instituições no Brasil. Revista de Administração Pública, v. 42, n. 6, p. 1041-1067, 2008.

SALAWAY, Gail; CARUSO, Judith Borreson; NELSON, Mark. The ECAR study of undergraduate students and information technology, ( Research Study), v. 8, O. Bouder, CO: EDUCAUSE Center for Applied Research, 2008. Disponível em: <https://net.educause.edu/ir/library/pdf/ers0808/rs/ers0808w.pdf>. Acesso em: 11 out. 2015.

SANTOS, Edméa. A cibercultura e a educação em tempos de mobilidade e redes sociais: conversando com os cotidianos. Práticas Pedagógicas, Linguagem e Mídias, p. 75 -98, 2011.

SARSAR, Firat; HARMON, Steve W. Facebook as a Learning Environment (FOLE): Graduate Students' Perspectives. In: Society for Information Technology \& Teacher Education International Conference. p. 3759-3763, 2012.

SARSAR, Firat; HARMON, Steve. Facebook as an Online Learning Environment: Perceptions of Undergraduate Students. In: Society for Information Technology \& Teacher Education International Conference. p. 715-720, 2011.

SPECIAL, Whitney T.; LI-BARBER, Kirsten T. Self-disclosure and student satisfaction with Facebook. Computers in Human Behavior, v. 28, n. 2, p. 624-630, 2012.

TSUKAMOTO, Neide M. Shimazaki; FIALHO, Neuza Nogueira; TORRES, Patrícia Lupion. A face educacional do Facebook: um relato de experiência. In: PORTO, Cristiane; SANTOS, Edmea (Orgs). Facebook e Educação. Publicar, curtir, compartilhar. Campina Grande: EDUEPB, p. 349-364, 2014.

VIDAL, Cinta Espunyet al. University students' attitudes towards and expectations of the Educational use of social netwoks. Revista de Universidad y SociedaddelConocimiento, v. 8, n. 1, p. 186-199, 2011

YAPICI, i. Ümit; HEVEDANLI, Murat. Educational use of social networks: Facebook case study. 2014. European Journal of Research on Education, Special Issue: Educational Technology and Lifelong Learning, 16-21, 2014. 